\title{
ANALISIS PERBANDINGAN KEKUATAN TARIK CONNECTING ROD ASLI DENGAN IMITASI PADA SEPEDA MOTOR
}

\author{
Rudi Saputra ${ }^{1}$, Arie Widjayanto ${ }^{2}$ \\ Program Studi Teknik Industri, Institut Sains dan Teknologi Nasional, Jakarta Selatan ${ }^{12}$ \\ email $^{1}$ : rudisaputra09@yahoo.com
}

\begin{abstract}
Abstrak
Pada kendaraan sepeda motor, connecting rod berfungsi untuk menghubungkan piston dengan crankshaft atau poros engkol, selanjutnya meneruskan tenaga yang dihasilkan oleh piston ke poros engkol. Pada saat ini banyak beredar connecting rod imitasi dimasyarakat, dimana pada connecting rod imitasi lebih cepat mengalami kerusakan dibandingkan connecting rod asli, itu dikarenakan adanya perbedaan mechanical properties yang tidak sesuai dengan standar nya. Tujuan dari penelitian ini dilakukan untuk mengetahui perbandingan nilai kekuatan tarik pada connecting rod asli dan imitasi. Dimana dilakukan beberapa metode pengujian untuk mengetahui perbedaan dari masing - masing sample diantaranya : uji komposisi kimia, uji metallografi, uji tarik. Dari hasil pengujian material connecting rod asli dan imitasi, hasil uji komposisi kimia diketahui kadar karbon (C) pada connecting rod asli sebesar $0.176 \%$ dan pada connecting rod imitasi sebesar $0.170 \%$. Selain itu unsur chromium $(\mathrm{Cr})$ pada connecting rod asli sebesar $1.15 \%$ dan pada connecting rod imitasi sebesar $0.933 \%$. Dari hasil uji metallografi pada connecting rod asli dan imitasi didapati fasa didominan dengan ferit dan pearlit. Hasil uji tarik pada connecting rod asli memiliki nilai rata - rata sebesar $1084.5 \mathrm{~N} / \mathrm{mm}^{\wedge} 2$ (Mpa) dan pada rata - rata nilai kekuatan tarik pada connecting rod imitasi sebesar $916.96 \mathrm{~N} / \mathrm{mm}^{\wedge} 2$ (Mpa).
\end{abstract}

Kata kunci: Connecting Rod, SCM 415 (JIS G 4105), komposisi kimia, kekuatan tarik, struktur mikro

\section{PENDAHULUAN \\ Latar Belakang}

Salah satu tujuan diciptakannya teknologi adalah untuk mempermudah manusia dalam memenuhi kebutuhan hidup. Hal ini dapat dirasakan dan dibuktikan dengan semakin mudahnya manusia melakukan sesuatu untuk memenuhi kebutuhan hidup. Terlepas dari dampak negatif yang timbul akibat penemuan dan penciptaan teknologi yang baru, sains dan teknologi sangat dibutuhkan oleh manusia. Sebagai contoh suatu perusahaan atau lembaga akan sangat kesulitan jika dalam ruang kerja tidak terdapat perangkat komputer untuk menyelesaikan tugas dan pekerjaan kantor maupun perusahaan. Kemajuan teknologi sekarang ini telah menghasilkan berbagai kreasi dalam segala hal yang bertujuan memudahkan segala aktifitas manusia. Ada berbagai sarana transportasi tersedia, mulai dari darat, udara, dan laut. Kendaraan yang diproduksi massal di negara kita umumnya kendaraan darat, salah satunya sepeda motor. Sepeda motor diproduksi agar dapat memudahkan pekerjaan manusia, maka diharapkan komponen sepeda motor didesain secara efektif dan efisien serta menggunakan material komponen yang berkualitas dan tahan lama.

\section{TINJAUAN PUSTAKA}

\section{Definisi Sepeda Motor}

Sepeda motor merupakan pengembangan dari sepeda konvensional yang lebih dahulu ditemukan. Di tahun 1868, Michaux ex Cie, suatu perusahaan pertama di dunia yang memproduksi sepeda dalam skala besar, mulai mengembangkan mesin uap sebagai tenaga penggerak sepeda. Namun usaha tersebut masih belum berhasil dan kemudian dilanjutkan oleh Edward Butler, seorang penemu asal inggris. Butler membuat kendaraan roda tiga dengan suatu motor melalui pembakaran dalam. Sejak penemuan tersebut, semakin banyak dilakukan percobaan untuk membuat motor dan mobil. Salah satunya dilakukan oleh Gottlieb Daimler dan Wilhelm Maybach dari jerman. 


\section{Connecting Rod}

Dalam mesin piston, connecting rod digunakan untuk menghubungkan piston dengan crankshaft atau poros engkol. Bersama - sama dengan poros engkol membentuk sebuah mekanisme yang mengubah gerakan linier piston menjadi gerakan rotasi. Gambar 2.1 menunjukkan connecting rod dari jenis kendaraan sepeda motor.

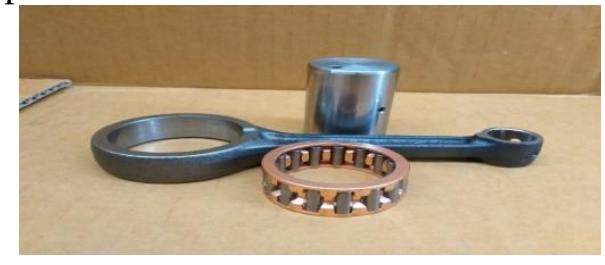

Gambar 2.1 Connecting Rod Sepeda Motor

\section{Bagian - Bagian dan Persyaratan Connecting Rod}

Connecting rod berfungsi untuk menghubungkan piston ke poros engkol dan selanjutnya meneruskan tenaga yang dihasilkan oleh piston ke poros engkol. Bagian ujung connecting rod yang berhubungan dengan pena piston disebut small end dan yang berhubungan dengan poros engkol disebut big end. Gambar 2.2 menunjukkan penampang dari connecting rod.

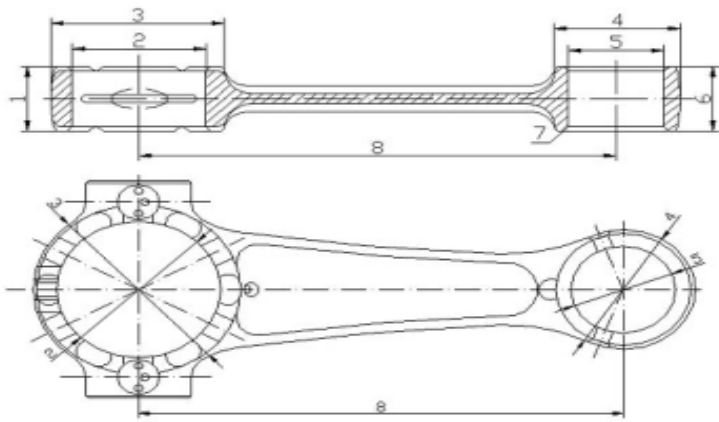

Gambar 2.2 Penampang Connecting Rod Sumber : Capt Engine Technology Inc, http : // mingyanggroup.2u.com.tw

1. $\quad$ Large-End Thickness

2. Large-End Bore Diameter

3. Large-End Outline Diameter

4. Small-End Outline Diameter

5. Small-End Bore Diameter

6. Small-End Thickness

$7 . \quad$ Chamfer

8. Distance of Two Center Lines

\section{Material Connecting Rod}

Material conneting rod adalah dari baja standard SCM-415/SCM-420 (JIS G 4105) dengan nilai kekuatan tarik sebesar $100 \mathrm{~kg} / \mathrm{mm}^{\wedge} 2$. Adapun nilai komposisi kimia nya sebagai berikut :
Tabel 2.1 komposisi kimia SCM 415 (JIS G 4105)

\begin{tabular}{|c|c|}
\hline Karbon (C) & $0.13 \%-0.18 \%$ \\
\hline Silikon $(\mathrm{Si})$ & $0.15 \%-0.35 \%$ \\
\hline Mangan $(\mathrm{Mn})$ & $0.60 \%-0.85 \%$ \\
\hline Fosfor $(\mathrm{P})$ & $0.030 \% \max$ \\
\hline Sulfur $(\mathrm{S})$ & $0.030 \% \max$ \\
\hline Cromium $(\mathrm{Cr})$ & $0.90 \%-1.20 \%$ \\
\hline Molybdenum $(\mathrm{Mo})$ & $0.15 \%-0.30 \%$ \\
\hline
\end{tabular}

Sumber : Jhon E. Bringas, Handbook Of Comparative World Steel Standard, ASTM DS67B, Edisi 3

\section{Pengertian Baja}

Baja adalah logam paduan, logam besi sebagai unsur dasar dengan karbon sebagai unsur paduan utamanya. Kandungan unsur karbon dalam baja berkisar antara 0,2\% hingga 2,1\% berat sesuai grade-nya. Fungsi karbon dalam baja adalah sebagai unsur pengeras dengan mencegah dislokasi bergeser pada kisi kristal (crystal lattice) atom besi. Baja karbon ini dikenal sebagai baja hitam karena berwarna hitam, banyak digunakan untuk peralatan pertanian misalnya sabit dan cangkul. Unsur paduan lain yang biasa ditambahkan selain karbon adalah titanium, krom (chromium), nikel, vanadium, cobalt dan tungsten (wolfram). Dengan memvariasikan kandungan karbon dan unsur paduan lainnya, berbagai jenis kualitas baja bisa didapatkan.

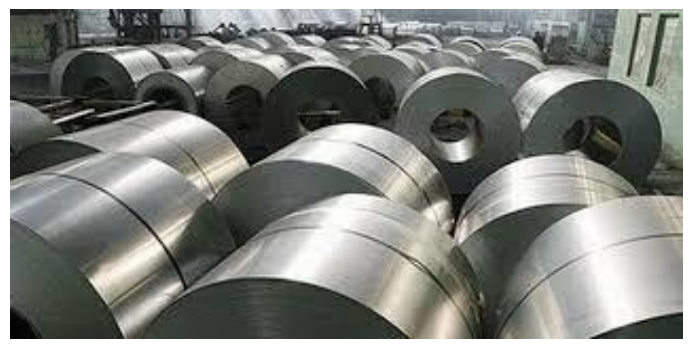

Gambar 2.3 Produk Baja

Penambahan kandungan karbon pada baja dapat meningkatkan kekerasan (hardness) dan kekuatan tariknya (tensile strength), namun di sisi lain membuatnya menjadi getas (brittle) serta menurunkan keuletannya (ductility).

\section{Jenis - jenis Bahan Baja}

Baja secara umum dapat dikelompokkan atas 2 jenis yaitu :

1. Baja karbon (Carbon steel)

2. Baja paduan (Alloy steel)

\section{Baja Karbon (Carbon Stell)}

Baja karbon digolongkan menjadi tiga kelompok berdasarkan banyaknya karbon yang terkandung dalam baja yaitu : 


\section{Baja karbon rendah (low carbon steel)}

Baja karbon rendah (low carbon steel) mengandung karbon antara $0.025 \%$ - 0,25\% C. Setiap satu ton baja karbon rendah mengandung 10 - $30 \mathrm{~kg}$ karbon. Baja karbon ini terdapat pada plat baja, baja strip dan baja batangan atau profil machine $(0,05 \%-0,30 \%$ C) sifat nya mudah ditempa dan mudah di mesim penggunaannya :

- 0,05\% - 0,20\% C : automobile bodies, buildings, pipes, chains, rivets, screws, nails.

- 0,20\% - 0,30\% C : gears, shafts, bolts, forgings, bridges, buildings.

Baja karbon menengah (medium carbon steel)

Baja karbon menengah (medium carbon steel) mengandung karbon antara 0,25\% - 0,55\% $\mathrm{C}$ dan setiap satu ton baja karbon mengandung karbon antara $30-60 \mathrm{~kg}$. Baja karbon menengah ini banyak digunakan untuk keperluan alat - alat perkakas bagian mesin.

- Kekuatan lebih tinggi dari pada baja karbon rendah.

- Sifatnya sulit untuk dibengkokkan, dilas, dipotong.

Penggunaan :

- 0,30\% - 0,40\% C : connecting rod, crank pins, axles.

- 0,40\% - 0,50\% C: car axles, cranksafts, rails, boilers, auger bits, screwdrivers.

- 0,50\%-0,60\% C: hammers dan sledges.

\section{Baja karbon tinggi (high carbon steel)}

Baja karbon tinggi (high carbon steel) mengandung kadar karbon antara $0,56 \%-1,7 \% \mathrm{C}$ dan setiap satu ton baja karbon tinggi mengandung karbon tinggi mengandung karbon antara $70-130$ $\mathrm{kg}$. Baja ini mempunyai kekuatan paling tinggi dan banyak digunakan untuk material tools. Sifatnya sulit dibengkokkan, dilas dan dipotong.

Penggunaan: Screw drivers, blacksmiths hummers, tables knives, screws, hammers, vise jaws, knives, drills. Tools for turning brass and wood, reamers, tools for turning hard metals, saws for cutting steel, wire drawing dies, fine cutters.

\section{Baja Paduan (Alloy Steel)}

Tujuan dilakukan penambahan unsur yaitu :

- Untuk menaikkan sifat mekanik baja (kekerasan, kekuatan tarik, keuletan, dll).

- Untuk menaikkan sifat mekanik pada temperatur rendah.

- Untuk meningkatkan daya tahan terhadap reaksi kimia (oksidasi dan reduksi).

menjadi :

Macam - macam baja paduan dibagi

\section{Low Alloy Steel}

Baja paduan rendah adalah salah satu klasifikasi dari baja paduan (alloy steel) yaitu : low alloy steel,medium alloy steel,dan high alloy steel. Klasifikasi ini dibedakan menurut unsur paduannya. Baja paduan rendah (low alloy steel) tergolong jenis baja karbon yang memiliki tambahan unsur paduan seperti Nikel, Chromium dan Molybdenum. Total unsur paduannya mencapai 2,07\%-2,5\%. Baja paduan rendah memiliki baja yang sedikit mengandung unsur paduan dibawah $10 \%$ dibandingkan dengan baja paduan tinggi mengandung unsur paduan diatas $10 \%$.

\section{Medium alloy steel}

Baja karbon medium mempunyai kandungan Karbon (C) $0,35 \% \div 0,5 \%$. Baja ini termasuk dalam kelompok baja yang dapat dibentuk dengan mesin dan dapat ditempa secara mudah, tetapi tidak bisa dilas semudah baja konstruksi dan baja struktural. Penambahan kandungan karbon akan mempertinggi kekuatan tarik tetapi mengurangi kemampuan regangnya. Baja karbon medium ini banyak digunakan apabila yang dipertimbangkan adalah kombinasi antara kekuatan dan kemampuan regang. Baja ini bisa digunakan untuk membuat shaft dan spindle (poros), crankshaft, axle, gear dan barang-barang tempa untuk komponen komponen lokomotif.

\section{High alloy steel}

Baja paduan tinggi (High Alloy Steel), merupakan baja paduan dengan kadar unsur paduan yang tinggi, mempunyai sifat khusus tertentu seperti baja tahan karat (Stainless Steel), baja perkakas (Tools Steel) misalnya high speed steel (HSS), baja tahan panas (Heat Resisting Steel) dan lain-lain.

\section{Sifat Baja}

Sifat baja pun berbeda - beda sesuai dengan hasil baja yang dibuat dan dibentuk. Dalam penggunaannya, baja mencapai $90 \%$ lebih dengan campuran untuk tujuan khusus. Baja dibuat dalam perbandingan (prosentase) zat arang yang berlainan. Semakin tinggi prosentase zat arangnya, maka baja menjadi :

a. Kekuatan tariknya bertambah.

b. Sifat regang berkurang.

c. Kekerasannya bertambah, juga sifat dapat dikeraskan maksimum $1,7 \%$ karbon.

d. Titik cair berkurang misal 0\% karbon titik cair $1539^{\circ} \mathrm{c} 17 \%$ karbon titik cair $1380^{\circ} \mathrm{c}$.

\section{Unsur - Unsur Pada Paduan Baja}

Baja pada asasnya adalah merupakan campuran besi dan karbon. Dimana kandungan karbon (C) mempengaruhi kekerasan baja, disamping itu, baja mengandung unsur campuran lain yang disebut paduan, misalnya Mangan ( Mn ), Tembaga ( $\mathrm{Cu}$ ), Silikon ( $\mathrm{Si}$ ), Belerang ( $\mathrm{S}$ ), dan posfor ( $\mathrm{P}$ ). 
Unsur - unsur tersebut mempunyai pengaruh pada baja yaitu :

\section{Carbon (C) :}

Mempunyai sifat keras tapi getas. Fungsi carbon pada baja adalah mampu menjalani reaksi - reaksi kimia seperti reaksi subtitusi (pergantian), reaksi adisi (penambahan), rekasi eliminasi (pengurangan). Carbon pada baja adalah sebagai lem atau zat perekat dan mempunyai sifat cukup tahan gesek terhadap benda atrasip ( tanah yang berpasir dan tidak mengandung silicon ). Carbon membuat/membentuk struktur ferit, dimana struktur tersebut mempunyai kekerasan diatas 48HRC, tetapi tidak mempunyai sifat ketajaman.

\section{Silicon (Si) :}

Mempunyai sifat elastis/keuletannya tinggi. Silicon juga menambah kekerasan dan ketajaman pada baja. Tapi penambahan silicon yang berlebihan akan menyebabkan baja tersebut mudah retak. Silicon berupa massa hitam mirip logam yang meleleh pada $1410^{\circ} \mathrm{C}$. Unsur ini mempunyai kecendrungan yang kuat untuk berkaitan dengan oksigen dan sifat seratnya tahan api.

\section{Mangan (Mn) :}

Mempunyai sifat yang tahan terhadap gesekan dan tahan tekanan (impact load). Unsur ini mudah berubah kekerasan nya pada kondisi temperatur yang tidak tetap dan juga digunakan untuk membuat alloy mangan tembaga yang bersifat ferromagnetic.

\section{Cromium (Cr) :}

Unsur ini digunakan sebagai pelindung permukaan baja dan tahan gesekan. Baja yang mengkilap, keras dan rapuh serta tahan terhadap korosi (karat) tetapi mempunyai keuletan yang rendah.

\section{Molybdenum (Mo) :}

Mempunyai sifat tahan pekerjaan panas sehingga cocok untuk hotwork tool steel, batas pencampuran ini max.7\% juga berfungsi sebagai penetralisir kekerasan wolfram. Molybdenum merupakan unsur tambahan pembuat keuletan baja yang maximum.

Nikel (Ni) :

Mempunyai sifat yang ulet dan tahan terhadap bahan kimia dan untuk mengatasi (karat) yang serius tetapi tidak mempunyai kekerasan yang tinggi. Merupakan unsur yang dicampurkan kedalam baja untuk mengatasi kerusakan pada temperatur tinggi (dapat mencapai $1200^{\circ} \mathrm{C}$ )

Vanadium (V) :

Baja berwarna putih perak dan sangat keras. Vanadium adalah bahan tambahan untuk pekerjaan panas karena sifat vanadium tahan terhadap gesekan pada temperatur yang tinggi.

Wolfarm (W) :
Diperlukan untuk ketajaman, tahan terhadap temperatur tinggi dan juga sangat tahan gesekan. Wolfarm mempunyai temperatur sepuh yang sangat tinggi dan memerlukan tempering berulang - ulang kali sehingga sangat sulit dalam pengolahan nya.

\section{Cobalt (Co) :}

Sifatnya tahan gesek dan tahan panas pada temperatur tinggi, kekerasan tinggi tapi getas. Berfungsi untuk membentuk carbide, meningkatkan kekerasan dan tahan panas yang sangat baik untuk ketajaman pada mata pisau.

\section{Struktur Mikro Baja}

Struktur dari baja karbon akan mempengaruhi pada sifat-sifat mekanik dan juga sifat fisik dari besi tersebut. Beberapa struktur yang ada dalam baja karbon adalah sebagai berikut :

\section{Ferrit}

Ferit adalah larutan padat karbon dan unsur paduan lainya pada besi kubus pusat badan (Fe). Ferit terbentuk akibat proses pendinginan yang lambat dari austenit baja hypotectoid pada saat mencapai A3 . ferrit bersifat sangat lunak, ulet dan memilikikekerasan sekitar 70-100 BHN dan memiliki konduktifitas yang tinggi.

\section{Sementit}

Sementit adalah senyawa besi dengan karbon yang umum dikenal sebagai karbida besi dengan prosentase karbon $6,67 \% \mathrm{C}$ yang bersifat keras sekitar 5 - 68 HRC.

\section{Perlit}

Perlit adalah campuran sementit dan ferit yang memiliki kekerasan sekitar 10-30HRC. perlit yang terbentuk sedikit dibawah temperatur eutektoid memiliki kekerasan yang lebih rendah dan memerlukan waktu inkubasiyang lebih banyak.

\section{Bainit}

Bainit merupakan fasa yang kurang stabil yang diperoleh dari austenit padatemperatur yang lebih rendah dari temperatur transformasi ke perlit dan lebih tinggi dari transformasi ke martensit.

\section{Martensit}

Martensit merupakan larutan padat dari karbon yang lewatjenuh pada besi alfa sehingga latis-latis sel satuanya terdistorsi.

Sistem Kesetimbangan $\mathrm{Fe}-\mathrm{C} \delta$

Diagram fasa Fe-C sangat penting di bidang metalurgi karena sangat bermanfaat di dalam menjelaskan perubahan-perubahan fasa Baja (paduan logam Fe-C). Baja merupakan logam yang banyak dipakai di bidang teknik karena kekuatan tarik yang tinggi dan keuletan yang baik. Paduan ini mempunyai sifat mampu bentuk (formability) yang baik dan sifat-sifat mekaniknya dapat diperbaiki dengan jalan perlakuan panas 
atau perlakuan mekanik. Untuk memudahkan di dalam memahami paduan $\mathrm{Fe}-\mathrm{C}$, terlebih dahulu akan dibahas sifat - sifat besi murni (Fe).

Besi Murni (Fe) Besi murni bersifat allotropy yaitu mempunyai berbagai bentuk kristal. Titik lebur besi sekitar $1539{ }^{\circ} \mathrm{C}$. Sedikit di bawah suhu $1539{ }^{\circ} \mathrm{C}$, besi cair mulai membeku dan membentuk fasa padat dengan struktur kristal bcc. Fasa padat ini dinamakan besi-S atau ferit- 8 sampai suhu sekitar $1401{ }^{\circ} \mathrm{C}$. Pada suhu antara 1401-910 ${ }^{\circ} \mathrm{C}$, struktur kristal besi berubah menjadi fcc yang dinamakan austenit (besi- $\square$ ). Selanjutnya di bawah $910{ }^{\circ} \mathrm{C}$, struktur kristal besi kembali ke bcc dalam bentuk ferit $\alpha$.

\section{Diagram Fasa Fe-C}

Diagram Fasa adalah diagram yang menampilkan hubungan antara temperatur dimana terjadi perubahan fasa selama proses pendinginan dan pemenasan yang lambat dengan kadar karbon. Tidak seperti struktur logam murni yang hanya dipergunakan oleh suhu, sedangakan struktur paduan dipengaruhi oleh suhu dan komposisi. Dibawah ini adalah bentuk dari diagram fasa pada baja karbon.

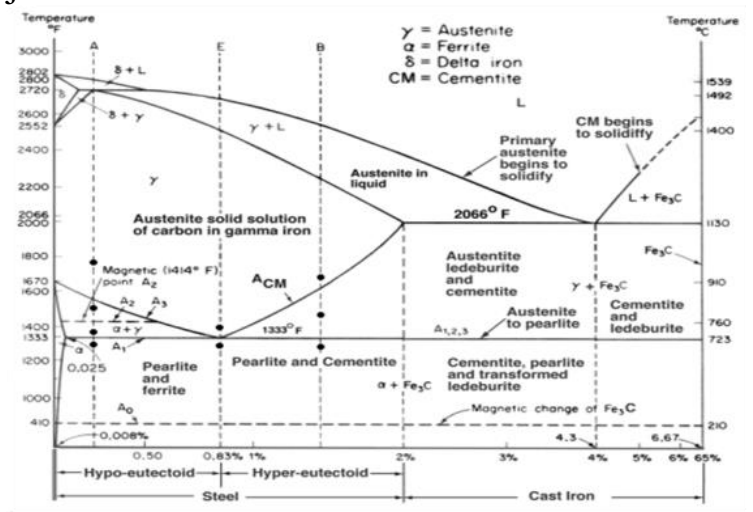

Gambar 2.4 Diagram fasa Fe-C

\section{Sifat Mekanik}

Sifat mekanik material, merupakan salah satu faktor terpenting yang mendasari pemilihan bahan dalam suatu perancangan. Sifat mekanik dapat diartikan sebagai respon atau perilaku material terhadap pembebanan yang diberikan, dapat berupa gaya, torsi atau gabungan keduanya. Dalam prakteknya pembebanan pada material terbagi dua yaitu beban statik dan beban dinamik. Perbedaan antara keduanya hanya pada fungsi waktu dimana beban statik tidak dipengaruhi oleh fungsi waktu sedangkan beban dinamik dipengaruhi oleh fungsi waktu. Untuk mendapatkan sifat mekanik material, biasanya dilakukan pengujian mekanik. Pengujian mekanik pada dasarnya bersifat merusak (destructive test), dari pengujian tersebut akan dihasilkan kurva atau data yang mencirikan keadaan dari material tersebut.
Sifat mekanik tersebut meliputi antara lain: kekuatan tarik, ketangguhan, kelenturan, keuletan, kekerasan, ketahanan aus, kekuatan impak, kekuatan mulur, kekeuatan leleh dan sebagainya.

\section{Uji Komposisi Kimia (Spectrometer Test)}

Uji komposisi kimia merupakan pengujian yang berfungsi untuk mengetahui seberapa besar atau seberapa banyak jumlah suatu kandungan yang terdapat pada suatu logam, baik logam ferro maupun logam non ferro. Uji komposisi biasanya dilakukan ditempat pabrik-pabrik atau perusahaan logam yang jumlah produksinya besar, ataupun juga terdapat di Instititut pendidikan yang khusus mempelajari tentang logam. Pengujian komposisi menggunakan spektrometer. Setiap unsur yang terkandung dalam suatu material akan memberikan pengaruh pada material tersebut, baik dari kekerasan (hardness), kekuatan (strength), keuletan (ductility), kelelahan (fatique) maupun ketangguhan (toughness). Dengan mengetahui komposisi kimia dari suatu material maka dapat diketahui sifat atau karakteristik dari material tersebut dan dibandingkan dengan referensi.

\section{Struktur Mikro}

Pengujian struktur mikro ini bertujuan untuk mempelajari dan mengetahui karakteristik struktur mikro dari logam, yang meliputi bentuk besar butiran, arah struktur dan distribusi berbagai tahapan dan inklusi yang memiliki efek besar pada sifat mekanik logam. Dengan metallografi dapat mengungkapkan perlakuan mekanik dan thermal yang terjadi pada logam, dan dapat dibuat untuk memprediksi perilaku dan kondisi yang diharapkan pada logam. Baja dengan butiran yang kasar cenderung kurang tangguh, namun baja jenis ini lebih mudah untuk pemesinan dan mempunyai kemampuan pengerasan yang lebih baik. Untuk baja yang berbutir halus, disamping lebih tangguh juga lebih ulet dibandingkan dengan yang berbutir kasar.

\section{Uji Tarik}

Uji tarik merupakan salah satu pengujian untuk mengetahui sifat - sifat suatu bahan. Dengan menarik suatu bahan akan segera mengetahui bagaimana bahan tersebut bereaksi terhadap tenaga tarikan dan mengetahui sejauh mana material itu bertambah panjang. Alat untuk uji tarik ini harus memiliki cengkraman (grip) yang kuat dan kekuatan yang tinggi (highly stiff). Pengujian tarik untuk kualitas kekuatan tarik dimaksud kan untuk mengetahui berapa nilai kekuatan dan perbandingan kekuatan tarik pada benda uji ( yang dimaksudkan bahan logam ).

Pembebanan tarik adalah pembebanan yang diberikan pada benda dengan memberikan gaya tarik berlawanan arah pada salah satu ujung 
benda. Untuk dimensi ukur bisa dilihat pada Gambar 2.5.

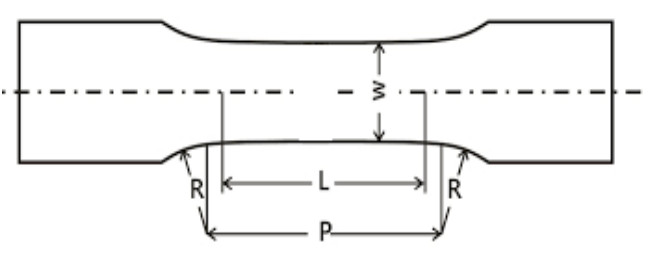

Gambar 2.5 Spesimen uji tarik

Pada pengujian tarik beban diberikan secara kontinyu dan pelan - pelan bertambah besar, bersamaan dengan itu dilakukan pengamatan mengenai perpanjangan yang dialami benda uji dan dihasilkan kurva tegangan - regangan. Tegangan dapat dihitung menggunakan rumus 1 : $\sigma \mathrm{u}=\mathrm{Fu} / \mathrm{Ao}$

Dimana :

$$
\begin{aligned}
\sigma \mathrm{u}= & \text { Tegangan normal }(\mathrm{kg} / \llbracket \mathrm{mm} \rrbracket \wedge 2) \\
\mathrm{Fu}= & \text { Beban maksimal }(\mathrm{kg}) \\
\mathrm{Ao}=\text { Luas penampang mula dari } & \text { penampang batang }(\llbracket \mathrm{mm} \rrbracket \wedge 2)
\end{aligned}
$$

Dan regangan (persentase pertambahan panjang) dapat dihitung menggunakan rumus 2 : $\varepsilon=\Delta \mathrm{L} /$ Lo X $100 \%=(\mathrm{L}-\mathrm{Lo}) / \mathrm{Lo} X 100 \%$

$$
\begin{aligned}
\text { Dimana : } & \varepsilon=\text { Regangan }(\%) \\
& \mathrm{L}=\text { panjang akhir }(\mathrm{mm}) \\
& \text { Lo }=\text { panjang awal }(\mathrm{mm})
\end{aligned}
$$

Pembebanan tarik dilakukan terus menerus dengan menambahkan beban sehingga akan mengakibatkan perubahan bentuk pada benda berupa pertambahan

\section{METODOLOGI DAN PENGOLAHAN DATA Prosedur Pengumpulan Data}

Pada pengumpulan data ini bertujuan untuk mengetahui bagaimana tahapan - tahapan untuk menganalisis perbandingan connecting rod asli dengan imitasi pada sepeda motor 4 tak/langkah. Tahapan - tahapan pada pengumpulan data ini yaitu :

\section{Pemilihan Judul}

Penentuan judul dilakukan untuk menentukan topik dan materi apa yang akan dibahas dalam penelitian ini

\section{Studi Literatur}

Studi literatur dilakukan untuk mencari materi dan teori yang berhubungan dengan penelitian ini dan memudahkan dalam menentukan proses yang akan dilakukan selama penelitian. Materi yang dibutuhkan antara lain pengertian connecting rod, pengertian bahan material, uji komposisi kimia, struktur mikro, uji tarik.

\section{Persiapan bahan}

Bahan yang digunakan pada penelitian ini adalah connecting rod asli dengan imitasi pada sepeda motor 4 tak/langkah.

4. Pengujian bahan

Pada pengujian bahan, bahan dibuat sepsimen dari connecting rod asli dengan imitasi pada sepeda motor 4 tak/langkah untuk dilakukan pengujian komposisi kimia, metallografi dan uji tarik.

5. Data pengujian

Pada data pengujian akan didapat nilai nilai atau struktur dari bahan material connecting rod asli dengan imitasi pada sepeda motor 4 tak/langkah.

\section{Analisa data}

Dilakukan setelah melakukan pengumpulan data dari bahan dasar sampai dengan melakukan pengujian-pengujian yang mendukung analisis yang akan dilakukan. Representasi data yang telah diolah berupa tabel dan foto. Selanjutnya setelah data selesai diolah, maka data tersebut dianalisis berdasarkan teori yang didapat dari referensi dan literatur.

7. Kesimpulan dan Saran

Menarik kesimpulan dari hasil pengolahan data dan analisis. Dan memberi saran untuk lanjutan dari penelitian ini.

\section{Peralatan yang Digunakan Alat Uji Komposisi Kimia}

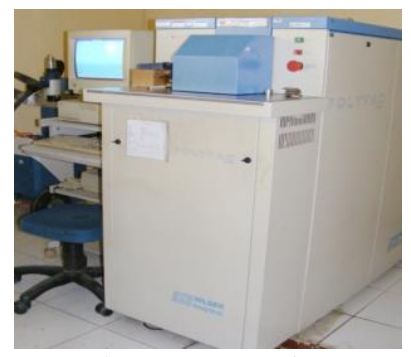

Gambar 3.1 Mesin Spectrometer

Alat uji komposisi kimia yang digunakan adalah spektrometer di Laboratorium Metallurgi Universitas Indonesia.

Alat Uji Metallografi

Mesin Amplas (centrifugal sand and paper machine)

Centrifugal sand and paper mechine digunakan untuk menghaluskan permukaan yang akan diuji metalografi. Penggunaan mesin ini dilakukan di Laboratorium Metallurgi Universitas Indonesisa Gambar 3.3 adalah gambar dari mesin amplas (Centrifugal sand and paper machine). 


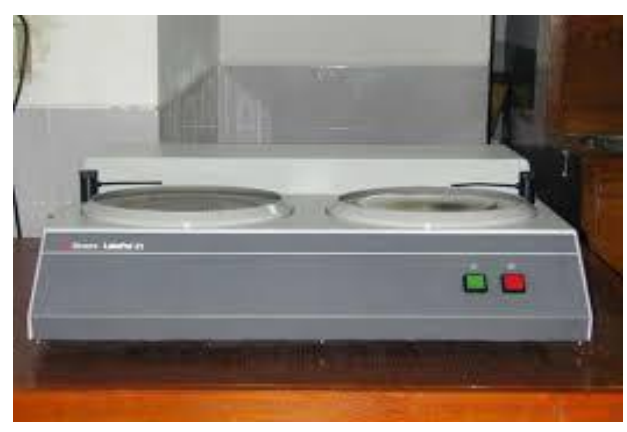

Gambar 3.2 Mesin Amplas

Mikroskop Optik dan Kamera

Mikroskop digunakan untuk mengamati struktur mikro dari spesimen dan kemudian mengambil foto setelah mendapatkan gambar yang diinginkan menggunakan kamera yang dilakukan di Laboratorium Metalografi Universitas Indonesia.


Gambar 3.3 Mikroskop dan Kamera

\section{Alat Uji Tarik}

Pengujian tarik bertujuan untuk mengetahui kekuatan tarik benda uji. Pengujian tarik untuk kekuatan tarik benda uji dimaksudkan untuk mengetahui perbedaan nilai kekuatan tarik pada connecting rod asli maupun imitasi. Pengujian tarik untuk kualitas kekuatan tarik dimaksudkan untuk mengetahui seberapa kuat benda tersebut menerima tarikan pada beban yang diberikan. Proses pengujian tarik dilakukan di lab BKI (Biro Klasifikasi Indonesia) dengan menggunakan alat uji tarik dapat dilihat pada Gambar 3.4.

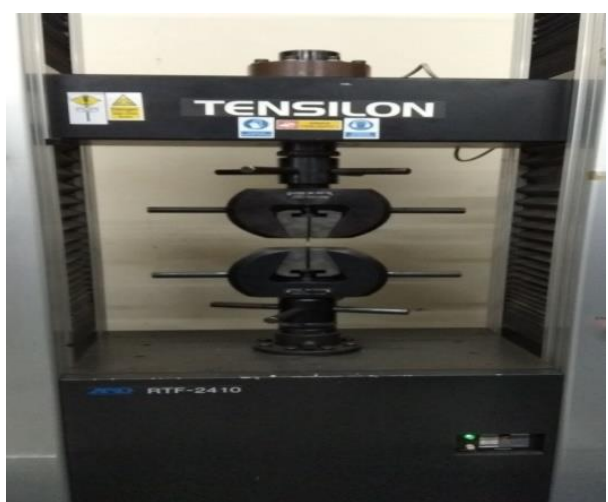

Gambar 3.4 Mesin Uji Tarik Tensilon RTF-2410 (Sumber ; PT. BKI)

\section{PENGOLAHAN DATA DAN PENGUJIAN \\ Data Pengujian Komposisi Kimia}

Setelah malakukan uji komposisi kimia pada Connecting Rod Asli dan Imitasi, Hasil pengujian komposisi kimia terdapat unsur pada connecting rod asli dengan nilai $\mathrm{C}$ (karbon) $0.176 \%, \mathrm{Si}$ (silikon) $0.162 \%, \mathrm{Mn}$ (mangan) $0.841 \%, \mathrm{P}$ (fosfor) $0.018 \%, \mathrm{~S}$ (sulfur) $0.014 \%, \mathrm{Cr}$ (chromium) $1.15 \%$, Mo (molybdenum) $0.156 \%$ dan connecting rod imitasi dengan nilai $\mathrm{C}$ (karbon) $0.170 \%, \mathrm{Si}$ (silikon) $0.213 \%, \mathrm{Mn}$ (mangan) $0.583 \%, \mathrm{P}$ (fosfor) $0.016 \%, \mathrm{~S}$ (sulfur) $0.007 \%, \mathrm{Cr}$ (chromium) $0.933 \%$, Mo (molybdenum) $0.167 \%$.

\section{Pengujian Metallografi}

\section{Pemotongan benda uji}

Agar mendapat bentuk struktur benda uji menggunakan mikroskop optik dengan baik, maka benda uji harus dipotong sesuai dengan standar alat uji metallografi. Pemotongan dilakukan sangat hati - hati agar tidak menimbulkan panas yang berlebihan yang bisa merubah struktur mikro dari benda yang akan diuji.

\section{Mounting}

Setelah dipotong benda uji kemudian dimounting yaitu benda uji dibingkai larutan campuran dari resin dan hardener, yang bertujuan untuk memudahkan pengoprasian selama proses preparasi grinding dan polishing.

\section{Grinding}

Setelah benda uji dimounting baru kemudian diampelas menggunakan mesin grinding, lalu ampelas yang digunakan adalah secara berurutan dari ukuran yang kasar sampai ukuran yang halus. Ukuran kertas ampelas yang digunakan adalah 220, 500, 1200, dan 1500 atau berurutan dari ampelas kasar sampai dengan ampelas yang halus, kertas ampelas terbuat dari bahan aluminium oxide (Water Proof). 
Proses grinding harus selalu dialiri dengan air bersih secara terus menerus dengan tujuan untuk menghindari timbulnya panas dipermukaan benda uji yang kontak langsung dengan kertas ampelas dan juga untuk menghindari partikel partikel bahan abrasive yang menempel pada permukaan benda uji.

\section{Polishing}

Proses polishing menggunakan mesin poles dan kain beludru ditempelkan pada piringan yang berputar melalui mesin poles, kemudian kain beludru tersebut diberi pasta alumina berupa partikel Abrasive yang sangat halus. Selama pemolesan benda uji digerakan kedepan dan kebelakang dengan maksud agar partikel partikel Abrasive dapat terdistribusi dengan merata diatas piringan pemoles setiap satu langkah pemolesan berakhir, benda uji harus senantiasa dicuci dan dikeringkan dengan udara hangat (Hair Dryer).

Benda uji yang telah dipoles kemudia harus diperiksa dibawah mikroskop untuk dilihat apakah masih ada goresan - goresan atau retakan, benda asing dan lain - lain. Polishing akan berakhir bila sudah diperoleh permukaan benda uji bebas dari goresan dan retakan lainnya hingga permukaan seperti cermin yang jernih.

Etsa

Setelah benda uji mengalami proses polishing kemudian dilakukan pengujian dengan larutan nital, dimana permukaan benda uji dicelupkan kedalam larutan nital 2\% (Alkohol 96\% $100 \mathrm{ml}+$ HNO_3 ml), setelah itu permukaan dibersihkan dengan air dan kemudian dicuci dengan alkohol 97\% dan dikeringkan dengan pengering udara, hal ini bertujuan agar terhindar dari oksidasi udara sekitar.

Pada dasarnya terjadi perubahan atau perkembangan struktur mikro yang terjadi selama proses etsa disebabkan oleh hal - hal sebagai berikut :

Perbedaan warna akibat distribusi struktur mikro.

Jenis kekerasan yang berbeda, akibat perbedaan orientasi kisi - kisi kristalnya.

Terbentuknya elemen lokal secara elektro kimia pada perbatasan kristal - kristal sebelum media etsa bereaksi dengan permukaan kristal tersebut.

\section{Pengamatan dan Pemotretan}

setelah proses pengetsaan selesai, lalu dilakukan pengamatan yaitu uji struktur mikro dengan menggunakan mikroskop dan dilakukan pemotretan dengan pembesaran 500X - 1000X.

Hasil Pengujian Struktur Mikro
(Metallografi)
Dibawah ini disajikan foto hasil struktur mikro (metallografi) perbesaran 500X dan 1000X pada Connecting Rod Asli dan Imitasi.

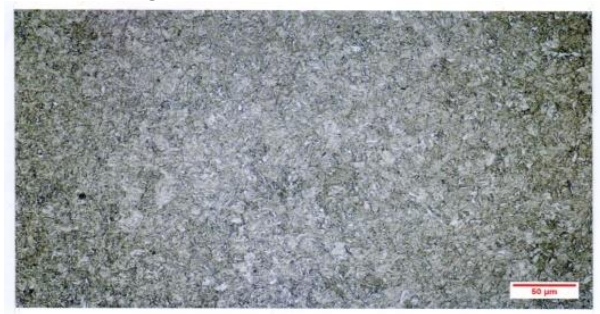

Gambar 3.5 Struktur Mikro Connecting Rod Asli Pembesaran 500X

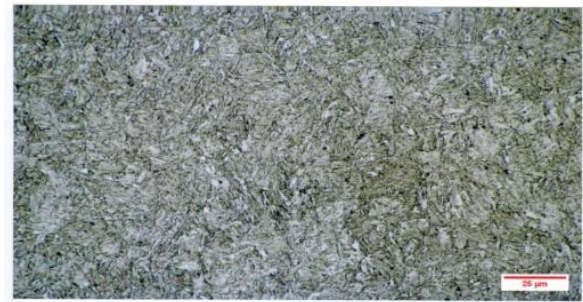

Gambar 3.6 Struktur Mikro Connecting Rod Asli Pembesaran 1000X

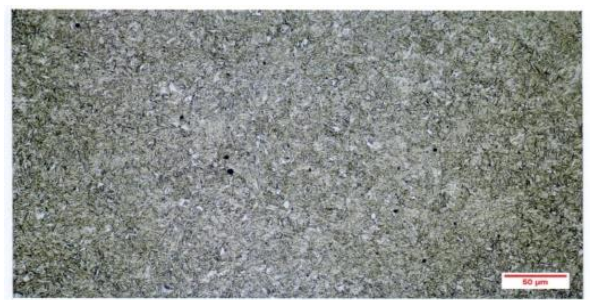

Gambar 3.7 Struktur Mikro Connecting Rod Imitasi Pembesaran 500X

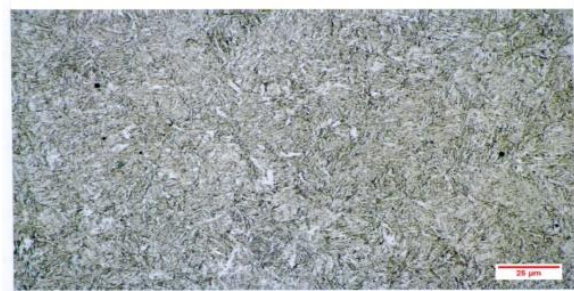

Gambar 3.8 Struktur Mikro Connecting Rod Imitasi Pembesaran 1000X

\section{Pengujian Tarik}

Proses pengujian tarik mengacu pada standar EN 10002-1 untuk pengujian kualitas kekuatan tarik. Setelah proses pembuatan spesimen pada benda uji, yang nantinya akan dilakukan uji tarik.

\section{Spesimen Hasil Uji Tarik}




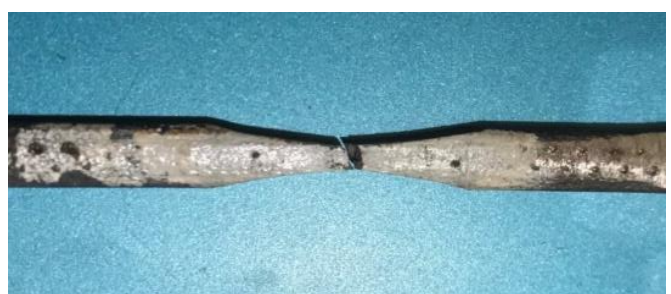

Gambar 3.9 Hasil Uji Tarik Connecting Rod Asli

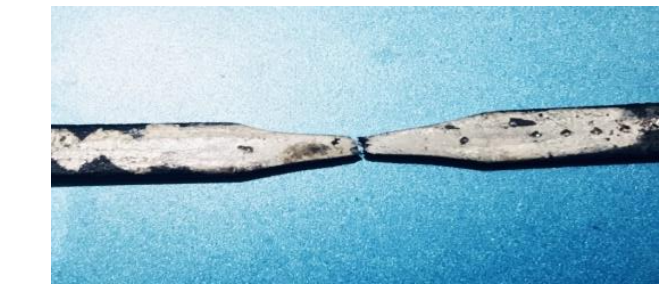

Gambar 3.10 Hasil Uji Tarik Connecting Rod Imitasi

Tabel 3.1 Hasil Pengujian Tarik Connecting Rod Asli dan Imitasi

\begin{tabular}{|c|c|c|c|c|}
\hline Spes & $\begin{array}{c}\text { Maks } \\
\text { Point } \\
\text { Load N }\end{array}$ & $\begin{array}{c}\text { Tensile } \\
\text { Strenght } \\
\mathrm{N} / \mathrm{mm}^{2} \\
(\mathrm{Mpa})\end{array}$ & $\begin{array}{c}\text { Rata- } \\
\text { Rata } \\
\mathrm{N} / \mathrm{mm}^{2}\end{array}$ & $\begin{array}{c}\mathcal{E} \\
(\%)\end{array}$ \\
\hline Asli & 9735.4 & 1081.7 & & 15.42 \\
\cline { 2 - 3 } \cline { 5 - 5 } & 8546.6 & 1087.4 & 1084.5 & 15.35 \\
\hline Imitasi & 8294.2 & 921.58 & & 15.00 \\
\cline { 2 - 3 } & 6842.5 & 912.34 & 916.96 & 14.29 \\
\hline
\end{tabular}

\section{ANALISIS DATA HASIL PENGUJIAN}

\section{Analisis Uji komposisi Kimia}

Dari hasil uji komposisi kimia yang telah dilakukan, diketahui bahwa kadar karbon yang terdapat pada connecting rod asli sebesar $0.176 \%$ dan pada connecting rod imitasi sebesar $0.170 \%$ ini berarti connecting rod asli memiliki kekuatan bahan yang lebih tinggi dibandingkan dengan connecting rod imitasi, karena sifat karbon yang dapat mengeraskan bahan atau juga sifatnya sebagai perekat dan mempunyai sifat cukup tahan gesek terhadap benda atrasip (tanah yang berpasir dan tidak mengandung silicon), unsur silicon ( $\mathrm{Si}$ ) pada connecting rod asli sebesar $0.162 \%$ dan connecting rod imitasi sebesar $0.213 \%$ ini menandakan connecting rod imitasi mempunyai sifat elastis dan keuletan nya lebih tinggi dibanding connecting rod asli, pada unsur mangan (Mn) connecting rod asli $0.841 \%$ dan connecting rod imitasi $0.583 \%$ ini menandakan connecting rod asli memiliki sifat yang tahan gesek dan tekanan (impact load) yang lebih tinggi, terlihat juga nilai Chromium (Cr) pada connecting rod asli jauh lebih tinggi dari pada connecting rod imitasi, yaitu $1.15 \%$ untuk yang asli dan $0.933 \%$ untuk yang imitasi. Ini menunjukan bahwa connecting rod asli memiliki proteksi/pelindung baik pada permukaan bahan maupun tahan terhadap korosi (karat) dibandingkan dengan connecting rod imitasi yang cendrung nilai chromium nya jauh lebih kecil.

Hasil komposisi kimia pada kedua bahan ini apabila dilihat dari diagram fasa baja karbon yaitu, bahan material ini termasuk dalam kategori baja hypoeutectoid yang memiliki nilai karbon sebesar $0.008 \%-0.83 \%$ dan memiliki kandungan fasa berupa pearlite dan ferrite dengan temperature pemanasan sebesar $1250^{\circ} \mathrm{C}$.

\section{Analisis Pengujian Struktur Mikro (Metallografi)}

Hasil dari uji struktur mikro dengan foto pembesaran 500X pada material Connecting Rod Asli dan Imitasi, foto metallografi ditunjukkan pada Gambar 4.1 dan 4.2.

\section{Struktur Mikro Connecting Rod Pembesaran} 500X.

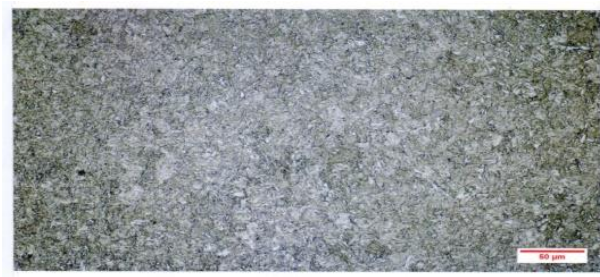

Gambar 4.1 Struktur Mikro Connecting Rod Asli

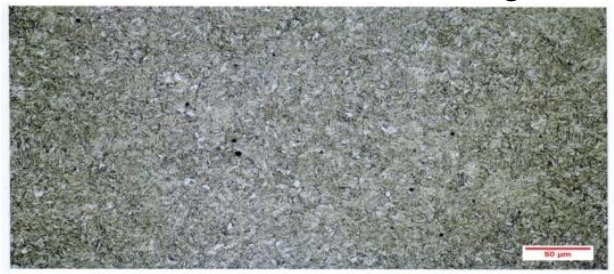

Gambar 4.2 Struktur Mikro Connecting Rod Imitasi

Pada gambar 4.1 dan 4.2 hasil metallografi pada connecting rod asli maupun imitasi dengan foto pembasaran 500X yaitu struktur mikronya sama sama didominasi dengan ferit dan perlit tidak ada perbedaan yang signifikan pada masing - masing struktur mikro.

Hasil dari uji struktur mikro dengan foto pembesaran 1000X pada material Connecting Rod Asli dan imitasi, foto metallografi ditunjukkan pada Gambar 4.3 dan 4.4.

Struktur Mikro Connecting Rod Pembesaran 1000X. 


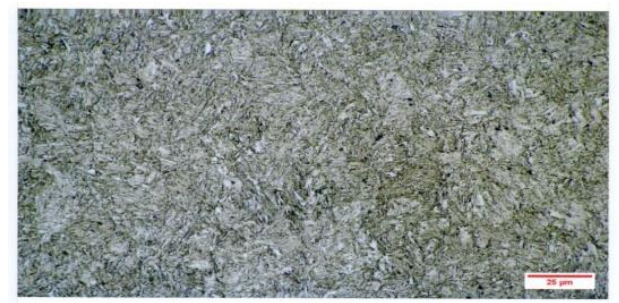

Gambar 4.3 Struktur Mikro Connecting Rod Asli

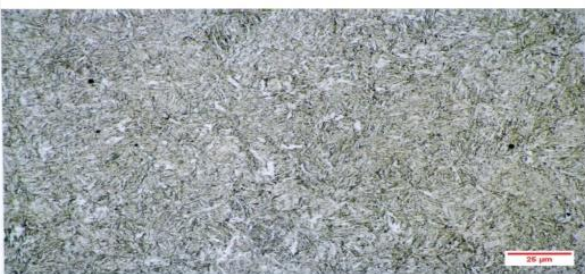

Gambar 4.4 Struktur Mikro Connecting Rod Imitasi

Pada gambar 4.3 dan 4.4 dengan foto pembesaran $1000 \mathrm{X}$ pada connecting rod asli struktur mikro nya tidak jauh berbeda dengan pembesaran 500X sama - sama didominasi dengan ferit dan perlit, namun pada struktur mikro connecting rod asli dengan pembesaran 1000X terlihat lebih didominan dengan perlit (struktur dengan warna gelap). Karna perbedaan nilai karbon yang diketahui pada uji komposisi kimia, maka pada struktur mikro connecting rod asli ada sedikit perbedaan dengan struktur mikro connecting rod imitasi dengan nilai kekerasan nya.

Analisis Uji Tarik

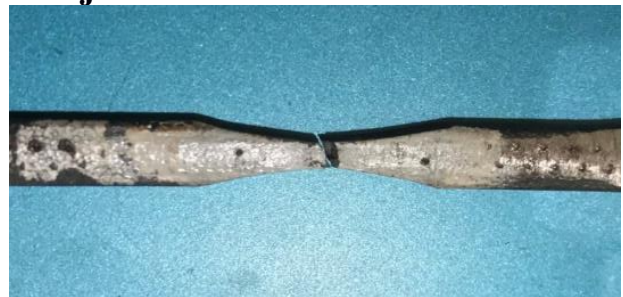

Gambar 4.5 Spesimen Hasil Uji Tarik Connecting Rod Asli

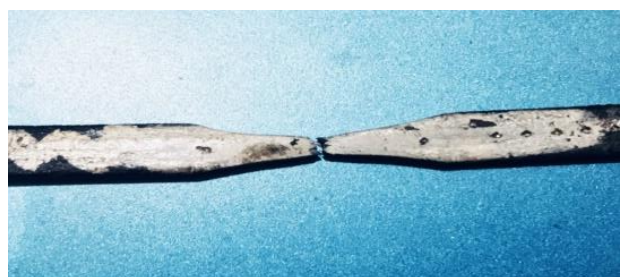

Gambar 4.6 Spesimen Hasil Uji Tarik Connecting Rod Imitasi

\section{Hasil Pengujian Tarik}

\begin{tabular}{|c|c|c|c|c|}
\hline \multirow{2}{*}{ Spes } & $\begin{array}{c}\text { Maks } \\
\text { Point } \\
\text { Load N }\end{array}$ & $\begin{array}{c}\text { Tensile } \\
\text { Strenght } \\
\mathrm{N} / \mathrm{mm}^{2} \\
(\mathrm{Mpa})\end{array}$ & $\begin{array}{c}\text { Rata- } \\
\text { Rata } \\
\mathrm{N} / \mathrm{mm}^{2}\end{array}$ & $\begin{array}{c}\varepsilon \\
(\%)\end{array}$ \\
\hline \multirow{2}{*}{ Asli } & 9735.4 & 1081.7 & \multirow{2}{*}{1084.5} & 15.42 \\
\cline { 2 - 3 } Imitasi & 8546.6 & 1087.4 & 15.35 \\
\cline { 2 - 3 } & 8294.2 & 921.58 & \multirow{2}{*}{916.96} & 15.00 \\
\cline { 2 - 3 } & 6842.5 & 912.34 & 14.29 \\
\hline
\end{tabular}

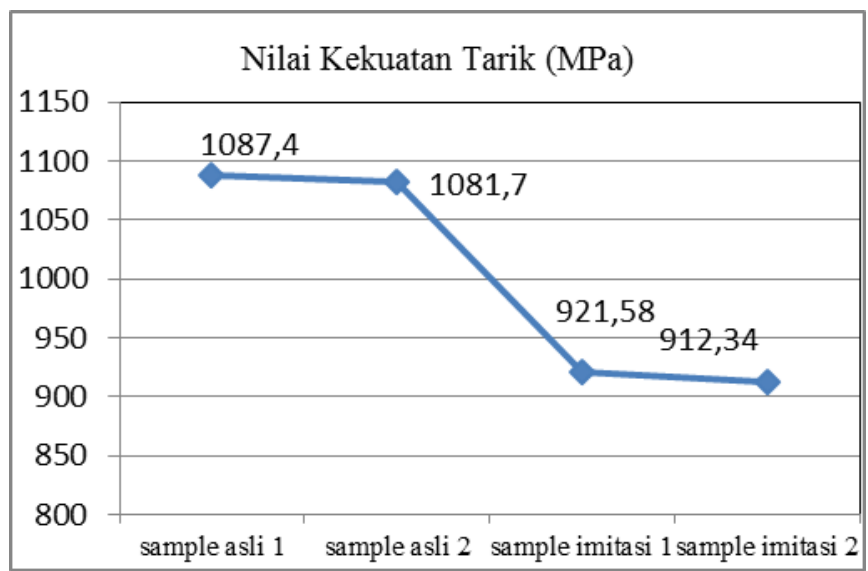

Data dari hasil bahwa hasil pengujian tarik untuk connecting rod sample asli 1 memiliki nilai kekuatan tarik sebesar $1087,4 \mathrm{~N} / \mathrm{mm}^{\wedge} 2$ dan pada sample asli ke 2 memiliki nilai kekuatan tarik sebesar 1081,7 $\mathrm{N} / \mathrm{mm}^{\wedge} 2$. Sedangkan pada connecting rod imitasi pada sample ke 1 memiliki nilai kekuatan tarik sebesar 921,58 N/mm^2 dan pada sample imitasi ke 2 memiliki nilai kekuatan tarik sebesar $912,34 \mathrm{~N} / \mathrm{mm}^{\wedge} 2$, ini menyatakan pada sample imitasi mengalami penurunan pada kekuatan tarik yang telah diujikan. Berdasarkan nilai kuat tarik yang diperoleh pada connecting rod asli berdasarkan kandungan unsur komposisi kimia pada Tabel 4.1 memiliki nilai karbon lebih tinggi dari connecting rod imitasi. Terlihat pada connecting rod asli memiliki nilai kekerasan dan kekuatan yang lebih dari imitasi namun tingkat keuletan menjadi rendah.

\section{KESIMPULAN}

Dari hasil penelitian, pengujian spesimen dan analisis data hasil pengujian maka dapat ditarik suatu kesimpulan, yaitu :

Hasil pengujian komposisi kimia terdapat unsur pada connecting rod asli dengan nilai $\mathrm{C}$ (karbon) $0.176 \%, \mathrm{Si}$ (silikon) $0.162 \%, \mathrm{Mn}$ (mangan) $0.841 \%, \mathrm{P}$ (fosfor) $0.018 \%, \mathrm{~S}$ (sulfur) $0.014 \%, \quad \mathrm{Cr} \quad$ (chromium) $1.15 \%, \quad \mathrm{Mo}$ (molybdenum) $0.156 \%$ dan connecting rod imitasi dengan nilai $\mathrm{C}$ (karbon) $0.170 \%, \mathrm{Si}$ (silikon) 
$0.213 \%, \mathrm{Mn}$ (mangan) $0.583 \%, \mathrm{P}$ (fosfor) $0.016 \%$, $\mathrm{S}$ (sulfur) $0.007 \%, \mathrm{Cr}$ (chromium) $0.933 \%$, Mo (molybdenum) $0.167 \%$.

Dari hasil uji komposisi kimia diketahui kadar karbon pada connecting rod asli sebesar $0.176 \%$ dan connecting rod imitasi $0.170 \%$ dan nilai molybdenum pada connecting rod asli sebesar $0.156 \%$ dan connecting rod imitasi sebesar $0.167 \%$ sehingga dapat digolongkan material tersebut adalah baja karbon - molybden dengan paduan rendah ditinjau dari kadar karbon nya.

Pada pengamatan metallografi dengan pembesaran 1000X didapatkan hasil bahwa struktur mikro pada connecting rod asli terdapat fasa ferit - perlit namun lebih didominasi dengan fasa perlit dan pada connecting rod imitasi terdapat fasa ferit - perlit dengan lebih mendominasi pada fasa ferit.

Hasil dari pengujian kekuatan tarik didapat nilai rata rata connecting rod asli sebesar 1084.5 $\mathrm{N} / \mathrm{mm}^{\wedge} 2$ dan imitasi sebesar $916.96 \mathrm{~N} / \mathrm{mm}^{\wedge} 2$, ini berhubungan dengan nilai perbandingan komposisi kimia yang menyatakan nilai kekerasan/kekuatan connecting rod asli lebih tinggi dibanding connecting rod imitasi.

\section{REKOMENDASI}

Pada dasarnya pemakaian connecting rod imitasi lebih didominan oleh masyarakat, karena harga yang relatif terjangkau namun umur pakai yang tidak tahan lama. Namun setelah melewati beberapa pengujian dan mendapatkan hasil mengenai perbandingan - perbandingan yang didapat pada material connecting rod asli dengan imitasi, penulis merekomendasikan untuk lebih menggunakan connecting rod asli. Jika dilihat dari hasil pengujian tingkat kekuatan pada material connecting rod asli jauh lebih besar dan memiliki umur pakai yang lebih dibanding dengan imitasi.

\section{DAFTAR PUSTAKA}

Erik Ardi Wicaksono, Perbedaan Sifat Mekanis Pada Sproket Gear Sepeda Motor Asli dan Imitasi, Institut Sains dan Teknologi Nasional, 2014

Supardi, R. (1997). Pengetahuan Material.

Sofyan, B. T. (2010). Pengantar Material Teknik. Salemba Teknika: Jakarta.

Adnyana, D.N, (2016). Kegagalan Dan Kerusakan Pada Komponen Mesin Dan Peralatan Industri, Vol.1, Institut Sains dan Teknologi Nasional

http://zircones.blogspot.com/2013/07/ pembuatanconnecting-rod.html
Julianto, B. (2012). Mekanisme Terjadinya Kegagalan Connecting Rod Sepeda Motor 2 Langkah, Institut Teknologi Indonesia.

Capt Engine Technology Inc, http://mingyanggroup. 2 u.com.tw

Bringas, J. E. (2002). Handbook of comparative world steel standards. ASTM. 